\title{
AHP- fuzzy comprehensive evaluation of the safety risk in power investment project along "the Belt and Road"
}

\author{
Taihua YANG, Zhixiang LI, Jing QIN \\ School of Economics \& Management, Shanghai University of Electric Power, 200090, Shanghai, China
}

\begin{abstract}
Energy is the focal point of "the belt and Road" investment cooperation. Because of the uncertainty factors, the safety risk of investment and construction is high, so the management and control of project is very difficult. Taking the $50 \mathrm{M}$ wind farm project in a South Asian country as an example, this paper constructs a safety risk assessment index system including 14 basic factors through the identification of the safety factors of "the belt and road" power investment project, and analyzes it by using the AHPfuzzy comprehensive evaluation method. The results show that the final safety risk evaluation score of a power investment project in a South Asian country belongs to the "medium risk" range. Geopolitical risk, national sovereignty risk, local legal risk and local natural environment risk are the main indicators, whose risk grade is relatively high. Finally, the paper puts forward the effective risk countermeasures and suggestions.
\end{abstract}

\section{Introduction}

"The Belt and Road" construction is a major initiative put forward by China, which is to build a new all-round opening pattern and deep integration into the world economic system. The aim is to promote the free flow of economic factors, the efficient allocation of resources and the deep integration of the market, and promote the coordination of economic policies among countries along the route. Carrying out a wider range, higher level, and deeper regional cooperation to jointly create an open, inclusive, balanced, and inclusive regional economic cooperation framework, and safeguarding the global free trade system and the open world economy is what it pursues. According to "Vision and actions on jointly building Belt and Road", the interconnection of infrastructure such as electricity is a priority area for the construction of "the Belt and Road". Investment in the construction of power facilities can optimize the allocation of power resources along "the Belt and Road", explore the potential of the market, promote investment and consumption, improve the efficiency of power resource development, effectively reduce the cost of power supply, create demand and employment, and achieve a win-win situation among participating countries([1]). China Export \& Credit Insurance Corporation's "Country Risk Analysis" carries out risk ratings for 192 sovereign countries around the world. Countries along "the Belt and Road" have high regional risks and the overall market environment is not very $\operatorname{good}([2])$. The complicated political environment, imperfect laws and regulations, and large cultural differences make the construction of power engineering project along "the Belt and Road" facing great risks([3]).
This paper selects the AHP-fuzzy comprehensive evaluation model to study the safety risks of the power investment project along "the Belt and Road".

\section{Modelling}

\subsection{Determining the factor domain of the evaluation object}

The power investment project safety risk is $U$, and its subset is $\mathrm{u}$, the number of evaluation indicators is $\mathrm{m}$ :

$$
U=\left\{u_{1}, u_{2}, \cdots u_{m}\right\}
$$

The above set indicates that there are $\mathrm{m}$ factors in the safety risk of the power investment project along "the Belt and Road".

\subsection{Establishing evaluation set}

The evaluation set is represented by $V: n$ represents the total number of evaluation results. Combining the risk characteristics of international projects with the research conclusions of previous scholars, this paper divides the safety risks of the power investment project along "the Belt and Road" into five levels, which are "minimum risk", "low risk", "medium risk", "high risk" and "maximum risk", evaluation set is $V=\left\{v_{1}, v_{2}, v_{3}, v_{4}, v_{5}\right\}$, Corresponding rank score is $\{1,2,3,4,5\}$ ([4]).

\subsection{Establishing membership matrix}

\footnotetext{
* Corresponding author: lizhixiang6344@163.com
} 
Analysis of the membership degree of the evaluated object from the perspective of single factor in each fuzzy

$$
\mathrm{R}=\left[\begin{array}{c}
r_{1} \\
r_{2} \\
\vdots \\
r_{m}
\end{array}\right]=\left[\begin{array}{cccc}
r_{11} & r_{12} & \cdots & r_{15} \\
r_{21} & r_{22} & \cdots & r_{25} \\
\vdots & \vdots & \ddots & \vdots \\
r_{m 1} & r_{m 2} & \cdots & r_{m 5}
\end{array}\right]
$$

$r_{k}=\left(r_{k 1}, r_{k 2}, \cdots, r_{k 5}\right)$ is the risk level evaluation vector of $u_{k}$. Where $r_{k j}$ represents the membership of the $k$ element $u_{k}$ to the risk level $v_{j}$. The risk level evaluation vector of each risk factor is given, and the evaluation membership matrix is obtained.

\subsection{Calculating index weight}

Dividing each risk factor into different levels through the above, constructing a corresponding evaluation membership matrix then, this paper uses the AHP method to calculate the index weights.

\subsubsection{Constructing judgement matrix}

The AHP method decomposes a target problem into several levels with inclusive relationships, quantifying qualitative problems through expert scoring. It requires decision makers to make judgments about the relative importance of each indicator element. This paper compares the indicator elements by means of expert investigation or brainstorming, and then constructs a comparison judgment matrix. Its form is as follows:

$$
\left[\begin{array}{cccc}
1 & a_{12} & \cdots & a_{1 m} \\
a_{21} & 1 & \cdots & a_{2 m} \\
\vdots & \vdots & \ddots & \vdots \\
a_{n 1} & a_{n 2} & \cdots & 1
\end{array}\right]
$$

Where $a_{i j}=\frac{a_{i}}{a_{j}}$ represents the ratio of the importance of the $i$ element to the $j$ element

\subsubsection{Calculating index weight}

Calculating the single-level weight vector and consistency test: Single-level sorting is to compare the elements of this layer with the elements of the previous layer, and then arrange the compared values in order to determine the largest eigenvector of the matrix. In this paper, the eigenvector is calculated by multiplication and addition, and each column element of the judgment matrix is normalized to obtain:

$$
\begin{gathered}
W=\left[\begin{array}{llll}
w_{1}, & w_{2}, & \ldots, & w_{n}
\end{array}\right]^{T} \\
W_{1}=\frac{\bar{W}}{\sum_{1}^{n} \bar{W}_{i}}, \quad(\mathrm{i}=1,2,3, \ldots, \mathrm{n})
\end{gathered}
$$

subset, constructing a fuzzy relation matrix then.

In order to test the logic between the indexes, a consistency check on the calculated weights is required. Calculating the random consistency ratio of the judgment matrix $C R$.If $C R<0.1$, That indicates that the matrix have consistency. For multi-order judgment matrix, as shown in Table 1.

Table 1. Average random consistency index of 1-15 order matrix

\begin{tabular}{lllllllll}
\hline$n$ & 1 & 2 & 3 & 4 & 5 & 6 & 7 & 8 \\
\hline$R I$ & 0 & 0 & 0.52 & 0.89 & 1.12 & 1.26 & 1.36 & 1.41 \\
$n$ & 9 & 10 & 11 & 12 & 13 & 14 & 15 & \\
$R I$ & 1.46 & 1.49 & 1.52 & 1.54 & 1.56 & 1.58 & 1.59 & \\
\hline
\end{tabular}

\subsection{Fuzzy comprehensive evaluation}

According to the above calculated risk factor weights and risk level membership matrix, select the appropriate fuzzy operator to calculate the fuzzy comprehensive evaluation value $S$.

$$
\begin{aligned}
S=W \cdot R= & \left(\begin{array}{llll}
w_{1} & w_{2} & \cdots & w_{m}
\end{array}\right) \cdot\left[\begin{array}{cccc}
r_{11} & r_{12} & \cdots & r_{1 n} \\
r_{21} & r_{22} & \cdots & r_{2 n} \\
\vdots & \vdots & \ddots & \vdots \\
r_{m 1} & r_{m 2} & \cdots & r_{m n}
\end{array}\right] \\
& =\left(s_{1}, s_{2}, \cdots S_{n}\right)
\end{aligned}
$$

After the above calculation, the evaluation vector $S$ needs to be processed to calculate the comprehensive score of the evaluation project. According to maximum membership degree law, if $S_{r}=\max \{b\}$ in fuzzy comprehensive evaluation result vector

$S=\left(s_{1}, s_{2}, \cdots s_{n}\right)$, the object to be evaluated is generally subordinate to the $r$-level.

\section{Establishment and Application of Safety Risk Evaluation Model for the Power Investment Project along "the Belt and Road"}

\subsection{Constructing "the Belt and Road" power investment project safety risk evaluation system}

A 50MW wind power project in South Asia along "the Belt and Road" has a total investment of 130 million US dollars. It is the first new energy project after the "Belt and Road" initiative. The project is located in the tropics, and there are sea breeze from the Arabian Sea all year round. From April to October every year, the maximum temperature can reach $50{ }^{\circ} \mathrm{C}$ and the average temperature is above $40^{\circ} \mathrm{C}$. In addition to the tough natural environment, under the high standards of foreign owners 
and supervisors, the project team encountered great challenges in terms of contract structure, project management mode, design and construction standards, financing and settlement methods, localized management, subcontractor management, and grid approval. The safety risks of power companies investing in power projects in the country along "the Belt and Road" mainly come from four aspects: political risk, economic risk, operational risk and natural risk, and established as the first-level index $U$ of the risk rating index system, the four aspects are established as four subsets of $U_{1}, U_{2}$, $U_{3}, U_{4}$, and $U=\left\{U_{1}, U_{2}, U_{3}, U_{4}\right\}$. Political risk $U_{1}$ contains two secondary indexes: geopolitical risk $U_{11}$ and national sovereign risk $U_{12}$. Economic risk $U_{2}$ contains four secondary indices: resource source risk $U_{21}$, change in exchange rate risk $U_{22}$, inflation and unemployment rate $U_{23}$, and estimated balance of payments as a percentage of GDP $U_{24}$. Operational risk $U_{3}$ contains four secondary indices, local laws affecting $U_{31}$, cultural impact $U_{32}$, social responsibility risk $U_{33}$, local human resource risk $U_{34}$. Natural risk $U_{4}$ contains four secondary indices: local harsh natural environmental risk $U_{41}$, local frequent natural disaster risk $U_{42}$, local infrastructure condition risk $U_{43}$ and local environmental protection risk $U_{44}$.

\subsection{Determining index factor weights}

This research selects 20 experts, scholars, and business executives who are authoritative in the field, and score according to their project experience. The judgment matrix is determined by each expert's judgment on the importance of each index. As is shown in Table 2-6:

Table 2. Judgment matrix of the criterion layer

\begin{tabular}{ccccc}
\hline$j$ & political risk & economic risk & operational risk & natural risk \\
\hline$i$ & & & & \\
\hline political risk & 1 & 1.19 & 1.27 & 1.13 \\
economic risk & 0.84 & 1 & 1.07 & 0.95 \\
operational risk & 0.79 & 0.93 & 1 & 0.89 \\
natural risk & 0.88 & 1.05 & 1.12 & 1 \\
\hline
\end{tabular}

Table 3. Judgment matrix belonging to political risk

\begin{tabular}{ccc}
$j$ & geopolitical risk & national sovereign risk \\
\hline$i$ & & 1.08 \\
geopolitical risk & 1 & 1 \\
\hline
\end{tabular}

Table 4. Judgment matrix belonging to economic risk

\begin{tabular}{lcccc}
\hline & $\begin{array}{c}\text { resource } \\
\text { source risk }\end{array}$ & $\begin{array}{c}\text { change in } \\
\text { exchange rate } \\
\text { risk }\end{array}$ & $\begin{array}{c}\text { inflation and } \\
\text { unemployment rate }\end{array}$ & $\begin{array}{c}\text { estimated balance of } \\
\text { payments as a } \\
\text { percentage of GDP }\end{array}$ \\
\hline $\begin{array}{l}\text { resource source risk } \\
\text { change in exchange } \\
\text { rate risk } \\
\text { inflation and }\end{array}$ & 1 & 1 & 1 & 1.09 \\
$\begin{array}{l}\text { unemployment rate } \\
\text { estimated balance of } \\
\text { payments as a percentage } \\
\text { of GDP }\end{array}$ & 1 & 1 & 1 & 1 \\
\hline
\end{tabular}

Table 5. Judgment matrix belonging to political risk

\begin{tabular}{|c|c|c|c|c|}
\hline$-j$ & $\begin{array}{l}\text { local laws } \\
\text { affecting }\end{array}$ & $\begin{array}{l}\text { cultural } \\
\text { impact }\end{array}$ & $\begin{array}{l}\text { social responsibility } \\
\text { risk }\end{array}$ & $\begin{array}{l}\text { local human } \\
\text { resource risk }\end{array}$ \\
\hline local laws affecting & 1 & 1.16 & 1.25 & 1.28 \\
\hline cultural impact & 0.86 & 1 & 1.08 & 1.1 \\
\hline $\begin{array}{l}\text { social responsibility } \\
\text { risk }\end{array}$ & 0.8 & 0.93 & 1 & 1.08 \\
\hline $\begin{array}{c}\text { local human resource } \\
\text { risk }\end{array}$ & 0.78 & 0.91 & 0.93 & 1 \\
\hline
\end{tabular}


Table 6. Judgment matrix belonging to political risk

\begin{tabular}{ccccc}
\hline & $\begin{array}{c}\text { local harsh natural } \\
\text { environmental risk }\end{array}$ & $\begin{array}{c}\text { local frequent } \\
\text { natural disaster } \\
\text { risk }\end{array}$ & $\begin{array}{c}\text { local infrastructure } \\
\text { condition risk }\end{array}$ & $\begin{array}{c}\text { local } \\
\text { environmental } \\
\text { protection risk }\end{array}$ \\
\hline $\begin{array}{c}\text { local harsh natural } \\
\text { environmental risk }\end{array}$ & 1 & 0.93 & 1.2 & 1.29 \\
$\begin{array}{c}\text { local frequent natural } \\
\text { disaster risk }\end{array}$ & 1.08 & 0.78 & 1.29 & 1.08 \\
$\begin{array}{c}\text { local infrastructure } \\
\text { condition risk }\end{array}$ & 0.83 & 0.72 & 0.93 & 1 \\
$\begin{array}{c}\text { local environmental } \\
\text { protection risk }\end{array}$ & 0.78 & 1 & 1.38 \\
\hline
\end{tabular}

Judgment matrix CR (The political risk judgment matrix is a second-order matrix, which is bound to be established. We ignore its CR) above is (0.0012451, $, 0.0007861,0.00067216,0.0010099)$, the $\mathrm{CR}$ values of the consistency check of each single-level index judgment matrix are less than 0.1 , indicating that the order of importance ranking of single-level indices is reasonable and acceptable.The weights are shown in Figure 1 :

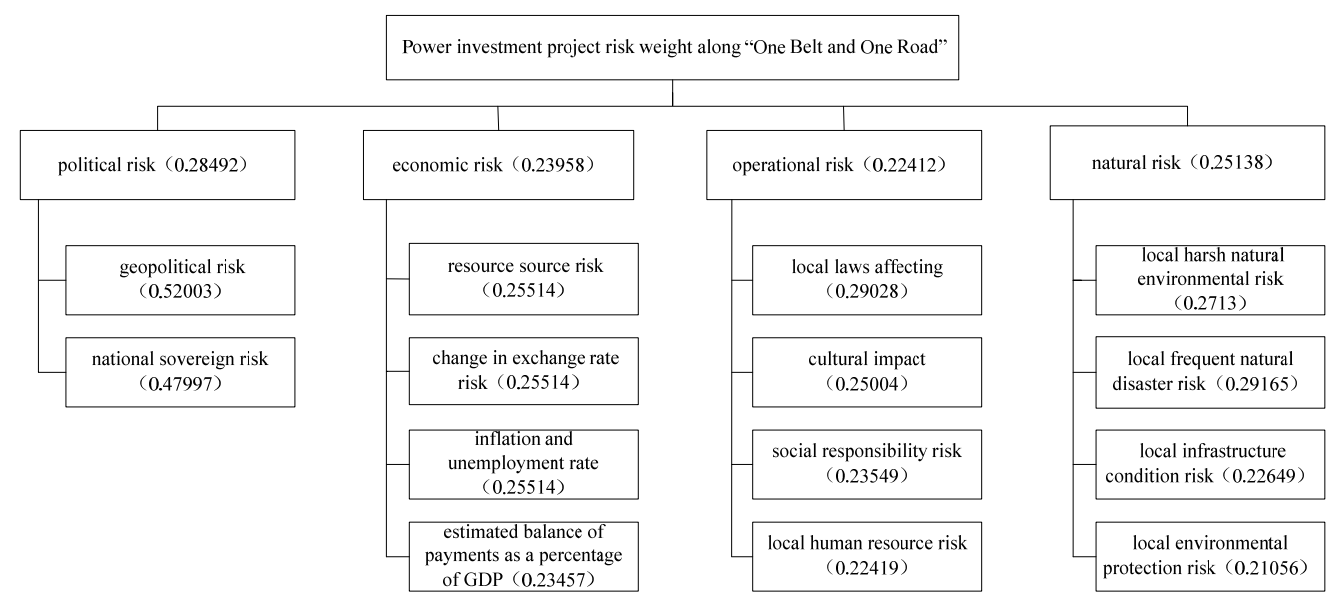

Figure 1. The power investment project safety risk evaluation system along "the Belt and Road"

\subsection{Fuzzy comprehensive evaluation of safety risks}

This paper constructs a subordinate subset of " $U_{1}, U_{2}$, $U_{3}, U_{4}$ ", and gives their respective fuzzy evaluation matrix $\mathrm{R}$, then perform the composite operation of the fuzzy matrix.

$$
\begin{aligned}
& s_{1}=w_{1} \cdot R_{1}=\left[\begin{array}{ll}
0.52003 & 0.47997
\end{array}\right] \cdot\left[\begin{array}{lllll}
0 & 0.1 & 0.3 & 0.45 & 0.15 \\
0 & 0.25 & 0.25 & 0.4 & 0.1
\end{array}\right] \\
& =\left[\begin{array}{lllll}
0 & 0.172 & 0.276 & 0.426 & 0.126
\end{array}\right] \\
& s_{2}=w_{2} \cdot R_{2}=\left[\begin{array}{llll}
0.25514 & 0.25514 & 0.25514 & 0.23457
\end{array}\right] \cdot\left[\begin{array}{lllll}
0.05 & 0.2 & 0.5 & 0.2 & 0.05 \\
0.1 & 0.2 & 0.35 & 0.3 & 0.05 \\
0.05 & 0.3 & 0.3 & 0.3 & 0.05 \\
0 & 0.35 & 0.55 & 0.1 & 0
\end{array}\right] \\
& =\left[\begin{array}{lllll}
0.051 & 0.2607 & 0.4224 & 0.2276 & 0.0383
\end{array}\right]
\end{aligned}
$$$$
s_{3}=w_{3} \cdot R_{3}=\left[\begin{array}{llll}
0.29028 & 0.25004 & 0.23549 & 0.22419
\end{array}\right] \cdot\left[\begin{array}{lllll}
0.05 & 0.2 & 0.35 & 0.3 & 0.1 \\
0.1 & 0.3 & 0.4 & 0.15 & 0.05 \\
0.1 & 0.4 & 0.4 & 0.05 & 0.05 \\
0.1 & 0.45 & 0.3 & 0.15 & 0
\end{array}\right]
$$

$=\left[\begin{array}{lllll}0.0855 & 0.3281 & 0.3631 & 0.17 & 0.0533\end{array}\right]$

$$
\begin{aligned}
& \mathrm{S}_{4}=w_{4} \cdot R_{4}=\left[\begin{array}{llll}
0.2713 & 0.29165 & 0.22649 & 0.21056
\end{array}\right] \cdot\left[\begin{array}{lllll}
0 & 0.3 & 0.3 & 0.15 & 0.25 \\
0 & 0.15 & 0.25 & 0.45 & 0.15 \\
0.15 & 0.1 & 0.6 & 0.1 & 0.05 \\
0.15 & 0.35 & 0.25 & 0.25 & 0
\end{array}\right] \\
& =\left[\begin{array}{lllll}
0.0656 & 0.2215 & 0.3428 & 0.2472 & 0.1229
\end{array}\right]
\end{aligned}
$$

Constructing the first-level fuzzy evaluation matrix:

$\theta=W \cdot S$

$$
\left[\begin{array}{llll}
0.28492 & 0.23958 & 0.22412 & 0.25138
\end{array}\right] \cdot\left[\begin{array}{lllll}
0 & 0.172 & 0.276 & 0.426 & 0.126 \\
0.051 & 0.2607 & 0.4224 & 0.2276 & 0.0383 \\
0.0855 & 0.3281 & 0.3631 & 0.17 & 0.0533 \\
0.0656 & 0.2215 & 0.3428 & 0.2472 & 0.1229
\end{array}\right]
$$$$
=\left[\begin{array}{lllll}
0.0479 & 0.2407 & 0.3474 & 0.2761 & 0.0879
\end{array}\right]
$$

Calculating the final evaluation score:

$$
\phi=\theta \cdot V=\left[\begin{array}{lllll}
0.0479 & 0.2407 & 0.3474 & 0.2761 & 0.0879
\end{array}\right] \cdot\left[\begin{array}{l}
1 \\
2 \\
3 \\
4 \\
5
\end{array}\right]=3.1154
$$

\section{Conclusion and Discussion}

This paper uses AHP and fuzzy comprehensive evaluation method to quantitatively evaluate the safety risk of the power investment project along the "Belt and Road". The final risk value is 3.1154 . It is closer to the 
medium risk interval. This result is consistent with the results of the actual investment construction risk situation of "Country-risk Rating of Overseas Investment from China"([5]) published by CASS.The conclusions of this paper support the idea that "the Belt and Road" is not only full of opportunities but also full of risks([6]). we can do the relevant risk prevention from the following aspects:

Our government should establish regular consultations and regular meeting mechanisms for regular consultations and top-level visits with countries along the route to promote China's international relations. We must rely on the "Belt and Road" to promote RMB settlement, expand the scale of local currency settlement in power investment, build an energy finance system, and reduce the risk of exchange rate of overseas business. The power companies can prevent investment risks by joint ventures, cooperation, business outsourcing, Compensation Trade, and commissioned Processing. The power companies need to increase research and development of power engineering disaster prevention and control technologies to reduce the impact of natural disasters on power project construction and ensure project safety.

\section{Acknowledgment}

The authors thank the financial support of the Shanghai Social Science Fund Project under grant No. 2016BGL001 and the National Social Science Fund Project under grant No. 17BGL010.

\section{References}

1. Y.C. Yang, Q.Y. Li, Q.Q. Zhao, Economic Review Journal, 99-104(2017)

2. X.F. Qi, X.J. Ding, Enterprise Management, 8587(2017)

3. S.R. Zhao, K.K. Yang, L.N. Long, Chinese Public Administration, 73-78(2018)

4. A.L. Yang, X. Zhong, Y.Y. Zhang, J.S. Wang, K.X. Yang, Resource Development \& Market, 35, 861866(2019)

5. CASS, Country-risk Rating of Overseas Investment from China , IIS,(2019)

6. F. Duan, Q. Ji, B.Y. Liu, Y. Fan, Journal of Cleaner Production, 535-547(2018) 